\title{
Tributo al Centenario
}

El 28 de enero de 1909 quedó constituida la Secretaría de Santidad y Beneficencia, que se creaba por la Ley Orgánica del Poder Ejecutivo (Decreto No. 87 de enero 12 de 1909). Este sería el primer organismo de la administración central de estado que se creaba en el mundo para atender los problemas de salud de la población. Hoy llega a su centenario con el nombre de Ministerio de Salud Pública.

A la creación de este organismo se llegó por la labor continua y bien fundamentada de un grupo de notables médicos salubristas cubanos, que desecharon la idea de reproducir en Cuba la organización de los Estados Unidos de América, que ocupaba el país con sus tropas y ejercía el gobierno interventor.

Las figuras más relevantes en nuestra historia de la salud pública, Carlos J. Finlay y J uan Guiteras Gener jugaron un importante papel, en lo que consideramos un notable acierto, confirmado con un siglo de trabajo con períodos luminosos y opacos.

Desde su creación hasta la cesantía (formalmente llamada renuncia) como Ministro de Juan Guiteras, transcurrió un período de notable éxito en el trabajo del organismo. Hechos como mantener controlada la fiebre amarilla y la viruela son muestras del buen trabajo de salud pública de la época.

Luego la política corrupta de sucesivos gobiernos llevó a la Secretaría al descrédito por su incompetencia para dar solución a los problemas sanitarios del país.

Con el triunfo revolucionario en 1959 se abrió el camino para la solución, a pasos rápidos y seguros, de los problemas de salud de la población cubana. La creación de un Sistema Nacional Único de Salud (1959-1969) ha sido la base de las conquistas en materia de salud colectiva de nuestro pueblo. Baste señalar la cifra de mortalidad infantil de 2008, con una tasa de 4,8 por mil nacidos vivos. Digna celebración del Cincuentenario de la Salud Pública Revolucionaria Cubana.

En el número uno de este año de la revista, se dedicaron varios artículos a presentar y comentar sucesos trascendentales de estos últimos cincuenta años de la salud pública en Cuba. En este número centramos nuestra atención en documentos y artículos que nos presentan el siglo del período de vigencia del Organismo de la Administración Central del Estado cubano para la salud de la población

De esta modesta forma rendimos tributo al trabajo, muchas veces heroico, de los millares de trabajadores del organismo que han hecho posible alcanzar el elevado nivel de salud que hoy goza la población cubana, y que llega también a otros 
pueblos, al hacerse efectivo nuestro principio de solidaridad internacionalista revolucionaria.

Francisco Rojas Ochoa 